\title{
Stenoparib, an inhibitor of cellular poly (ADP-ribose) polymerase (PARP), blocks 2 replication of the SARS-CoV-2 human coronavirus in vitro.
}

4 Nathan E. Stone ${ }^{\mathrm{a}}$, Sierra A. Jaramillo ${ }^{\mathrm{a}}$, Ashley N. Jones ${ }^{\mathrm{a}}$, Adam J. Vazquez ${ }^{\mathrm{a}}$, Madison Martz ${ }^{\mathrm{a}}$, Lora M. Versluis $^{\mathrm{ab}}$, Marlee O. Raniere ${ }^{\mathrm{ab}}$., Haley E. Nunnally ${ }^{\mathrm{a}}$, Katherine E. Zarn ${ }^{\mathrm{a}}$, Roxanne

6 Nottingham $^{\mathrm{a}}$, Jason W. Sahl ${ }^{\mathrm{ab}}$, David M. Wagner ${ }^{\mathrm{ab}}$, Steen Knudsen ${ }^{\mathrm{c}}$, Erik W. Settles ${ }^{\mathrm{ab}}$, Paul S. Keim $^{\mathrm{ab}}$, Christopher T. French ${ }^{\mathrm{ab} \# .}$

8

aPathogen and Microbiome Institute, Northern Arizona University, Flagstaff, AZ 86011-4073

${ }^{b}$ Department of Biological Sciences, Northern Arizona University, Flagstaff, AZ 86011-5640

cAllarity Therapeutics, DK-2970 Hørsholm, Denmark

12

Running Head: Stenoparib inhibits SARS-CoV-2 in vitro

\#Address correspondence to Christopher T. French, ctfrench@nau.edu

\section{ABSTRACT}

By late 2020, the coronavirus disease (COVID-19) pandemic, caused by SARS-CoV-2 has caused tens of millions of infections and over 1 million deaths worldwide. A protective vaccine and more effective therapeutics are urgently needed. We evaluated a new PARP inhibitor, stenoparib, which was recently advanced to Stage II clinical trials for treatment of

22 ovarian cancer, for activity against human respiratory coronaviruses, including SARS-CoV-2, in vitro. Stenoparib exhibits dose-dependent suppression of SARS-CoV-2 multiplication and spread 24 in Vero E6 monkey kidney and Calu-3 human lung adenocarcinoma cells. Stenoparib was also 
strongly inhibitory to the $\mathrm{HCoV}-\mathrm{NL} 63$ human seasonal respiratory coronavirus. Compared to

26 remdesivir, which inhibits viral replication downstream of cell entry, stenoparib impedes entry and post-entry processes as determined by time-of-addition (TOA) experiments. Moreover, a 10

$28 \mu \mathrm{M}$ dosage of stenoparib - below the approximated $25.5 \mu \mathrm{M}$ half-maximally effective concentration $\left(\mathrm{EC}_{50}\right)$, combined with $0.5 \mu \mathrm{M}$ remdesivir suppressed coronavirus growth by more

30 than $90 \%$, indicating a potentially synergistic effect for this drug combination. Stenoparib as a standalone or as part of combinatorial therapy with remdesivir should be a valuable addition to 32 the arsenal against COVID-19. 


\section{Importance}

New therapeutics are urgently needed in the fight against COVID-19. Repurposing drugs that are either already approved for human use or are in advanced stages of the approval process can facilitate more rapid advances toward this goal. The PARP inhibitor stenoparib may be such a drug, as it is currently in Stage II clinical trials for the treatment of ovarian cancer and its safety and dosage in humans has already been established. Our results indicate that stenoparib possesses strong antiviral activity against SARS-CoV-2 and other coronaviruses in vitro. This

42 activity appears to be based on multiple modes of action, where both pre-entry and post-entry viral replication processes are impeded. This may provide a therapeutic advantage over many

44 current options that have a narrower target range. Moreover, our results suggest that stenoparib and remdesivir in combination may be especially potent against coronavirus infection. 


\section{Introduction}

The novel SARS-CoV-2 coronavirus emerged from Wuhan, China in late 2019, and

50 rapidly spanned the globe in a devastating pandemic (1). The disease, COVID-19, compromises the upper and lower respiratory systems and may affect all people (2). Although in many cases COVID-19 symptoms may be mild, some patients present with pulmonary distress leading to severe lung damage, and treatment options are limited (1, 3-5). Mortality estimates range from $0.5 \%$ to more than $5 \%(6)$. According to the Johns Hopkins COVID Resource Center (7), as of Nov. 10, 2020, over 10 million infections and more than 240,000 deaths have occurred due to COVID-19 in the USA alone, and the pandemic continues (8). A protective vaccine may become available $(1,2)$, but unless sufficient immunity can be achieved in the population, COVID-19 has the potential to cause morbidity and mortality for years to come. Without a protective vaccine, COVID-19 has largely been controlled through non-pharmaceutical measures such as quarantine, social isolation, and the use of personal protective equipment. Clearly, more efficacious treatments are needed. transmission, where inhaled droplets containing infectious virions are seeded into the respiratory

64 tract (1). The virions bind to respiratory epithelium via the affinity of the virus spike (S) complex to the angiotensin converting enzyme 2 (ACE2) receptor (9). A cellular serine protease the viral and cellular plasma membranes and internalization of the virus-receptor complex by endocytosis. Subsequently, the virus is uncoated and releases its single-stranded RNA genome, which is processed, translated, and replicated in the host cytosol. Copies of the viral genome are 
the cell $(11,12)$. The SARS-CoV-2 lifecycle is typical of other coronaviruses, including the

Conservation of key steps in the coronavirus viral lifecycles potentially constitutes an 'Achilles

74 Heel' that is broadly susceptible to therapeutic intervention.

Antiviral therapeutics impede interactions between the virus and the host cell. Potential

76 targets include the virus binding to the cellular receptor, viral entry or virus-host membrane fusion, viral transcription, translation, replication and export. (1). Stenoparib is an

78 investigational, orally-available small molecule that inhibits poly (ADP-ribose) polymerase (PARP), a key enzyme in DNA repair (13). Stenoparib is unique in that it has dual inhibitory

80 activity against the PARP $1 / 2$ and tankyrase $1 / 2$ enzymes, which are important regulators of the canonical Wnt/ $\beta$-catenin checkpoint that is often dysregulated in metastatic breast cancer (14).

82 Until August 2020, stenoparib was known as "2X-121" and previously as "E7449". Recently, another PARP inhibitor mefuparib (CVL218) was shown to inhibit SARS-CoV-2 in vitro.

84 CVL218 suppressed SARS-CoV-2 infection in Vero E6 African Green Monkey cells (15). As implied by molecular modeling studies, CVL218 and other PARP inhibitors may block viral replication by interfering the viral nucleocapsid (N) protein binding to an RNA template (15).

The practice of repurposing existing drugs for new indications has advantages over

88 developing an entirely new drug $(16,17)$. There are numerous repurposed drugs in use, including zidovudine, which was repurposed from the treatment of cancer to treat HIV/AIDS; the epilepsy

90 drug topiramate, which is used to treat obesity; aspirin for analgesia and the prevention of colorectal cancer, among other examples (16). With repurposing, the risk of failure is lower

92 compared to developing a new drug, because safety trials have already been completed and the in vivo pharmacokinetics have been characterized; thus, cost and time of development are reduced. 
94 Moreover, the repurposing endeavor itself may reveal new disease targets and pathways. Altogether, reproposing can produce more rapid and efficient returns $(16,18)$. Stenoparib is

96 currently in Phase II clinical trials for the treatment of ovarian cancer (14). Based on the recent promising results of the PARP inhibitor CVL218 against SARS-CoV-2 in vitro (15), we

98 evaluated the activity of stenoparib against SARS-CoV-2, with an eye toward its use as a treatment for COVID-19. 


\section{Results}

Stenoparib inhibits the replication of SARS-CoV-2 in Vero E6 cells. Based on the

104 reported antiviral activity of other PARP inhibitors on SARS-CoV-2 in vitro (15) we aimed to determine whether stenoparib possessed a similar activity against the virus. Stenoparib was

106 prepared as a solution in dimethylsulfoxide (DMSO) and used to treat Vero E6 cells infected with SARS-CoV-2 (USA-WA1/2020). Vero E6 is a common cell platform for propagating coronaviruses, including SARS-CoV-2 and SARS-CoV $(19,20)$. At 48 hours (h) after infection, RNA was isolated from cell supernatants, and viral copy number was estimated by reverse-

110 transcription quantitative real-time polymerase chain reaction (RT-qPCR). Viral RNA measurements were compared to untreated cell controls, and to infected cells treated with a

112 cocktail of camostat mesylate and $\mathrm{E} 64 \mathrm{~d}($ ' $\mathrm{C} / \mathrm{E}$ '), which are protease inhibitors that impede processing of the virus spike protein and interfere with its entry into the cell $(10,21)$. In parallel,

114 we assessed potential toxic effects of stenoparib using the lactate dehydrogenase release assay, which indicates cytotoxicity due to cell lysis. As shown in Fig. 1, stenoparib demonstrated dose-

116 dependent activity against SARS-CoV-2 at concentrations up to $30 \mu \mathrm{M}$ with negligible cytotoxicity. The significant $63.2 \%$ reduction in viral load following treatment $(\mathrm{t}=8.608$,

$118 \mathrm{P}=0.0010)$ is comparable to the results reported for the CVL218 PARP inhibitor (35.2-99.7\% inhibition) at comparable concentrations (15).

At concentrations higher than $30 \mu \mathrm{M}$, and treatment durations exceeding $48 \mathrm{~h}$, stenoparib displayed marked cytotoxicity to Vero E6 cells (Fig. 2A), which limited our capacity to

122 comprehensively test the activity of the drug. We used a stenoparib response software predictor to pre-assess the susceptibility of human tumor cells based on the quantitative activity of 414 124 genes (22). When applied to human cell lines used with SARS-CoV-2 (23), the algorithm 
predicted that LLC-MK2 cells would be less sensitive to stenoparib toxicity than Vero E6 cells.

126 The cell line Calu-3, originally isolated from the pleural effusion of a patient with lung adenocarcinoma (24), was predicted to be even more resistant than LLC-MK2. We verified this

128 prediction for Calu-3 cells using stenoparib concentrations up to $60 \mu \mathrm{M}$, and exposure for up to $120 \mathrm{~h}$, with no elevation in cytotoxicity over baseline conditions $(\mathrm{t}=8.237, \mathrm{P}=0.0144)$ (Fig. 2B).

more resistant to the toxic effects of stenoparib than Vero E6 cells, we utilized Calu-3 cells to

132 test the effectiveness of higher doses than were previously achievable with Vero E6. The viral plaque assay comprehensively assesses inhibitors on the viral intracellular lifecycle, from virus

134 entry, to multiplication, and cell to cell spread. Plaques result from cell damage and death following infection, appearing as empty regions or "dead zones" in the cell monolayer (25).

136 Fresh media containing $2 \%$ FBS, with or without stenoparib or C/E control inhibitors, was applied to confluent monolayers of Calu-3 cells, which were then infected with SARS-CoV-2 for

$1381 \mathrm{~h}$. At this time the infection media was removed, and the cells were overlaid with a semisolid matrix consisting of cell growth medium in $1.2 \%$ low melting temperature agarose, with or

140 without stenoparib or control inhibitors. At $120 \mathrm{~h}$ post infection, cells were fixed with paraformaldehyde, stained with crystal violet, and the number of plaques were visually counted.

142 As shown in Fig. 3A (see also Fig. S1), treatment with $30 \mu \mathrm{M}$ stenoparib resulted in a 30.6\% reduction of plaque forming units (PFUs) per well compared to infected, untreated cells $(\mathrm{t}=3.054$, $144 \mathrm{P}=0.0379)$. Using a higher dose of $60 \mu \mathrm{M}$ stenoparib, we observed near complete inhibition of plaque formation $(94.0 \% ; \mathrm{t}=10.24, \mathrm{P}=0.0005)$ with no significant cytotoxicity $(\mathrm{t}=0.446$,

$146 \mathrm{P}=0.6992$ ), approaching the effect of the $\mathrm{C} / \mathrm{E}$ control inhibitor (Fig. S1). These observations are mirrored by the results from RT-qPCR, which showed an $80.6 \%$ reduction of viral copy number 
148 with $60 \mu \mathrm{M}$ stenoparib $(\mathrm{P}<0.0001)$. These observations affirm the prediction that Calu-3 cells are more resistant to the effects of stenoparib than Vero E6 cells and are suitable hosts for SARS-

150 CoV-2 in vitro. It is interesting to speculate that Calu-3 cells may exhibit a degree of resistance to conditions that can be rapidly toxic in other, more rapidly dividing cell lines, which warrants

152 further exploration. Indeed, the in vitro doubling time of Calu-3 cells ( $>60 \mathrm{~h})$ was notably slower than either the Vero E6 ( $24 \mathrm{~h})$ or the LLC-MK2 $(\sim 36 \mathrm{~h})$ cell lines.

The NL63 virus as a surrogate in vitro model. In addition to SARS-CoV-2, several other human coronaviruses, including SARS-CoV, interact with human cells via the ACE2

156 receptor, and multiply intracellularly utilizing similar pathways (9). This group includes the respiratory coronavirus $\mathrm{HCoV}-\mathrm{NL63}$ (or just 'NL63'), which is a cause of the seasonal colds in 158 humans. While symptoms are generally mild, NL63 infections can be serious in infants and immunocompromised individuals (26-28). Based on its relatedness to SARS-CoV-2, and to 160 establish a surrogate system for use in Biosafety Level-2 (BSL-2) instead of BSL-3 laboratory conditions, we evaluated NL63 for testing the effects of stenoparib. The NL63 virus (NR-470) was propagated in LLC-MK2 Rhesus macaque kidney cells (29). Viral replication levels were assessed by plaque assay and RT-qPCR as performed for

164 SARS-CoV-2. Controls were infected/untreated cells, and infected cells treated with the C/E inhibitor cocktail. Overall, the effects of stenoparib on NL63 corroborated the results of our

166 experiments with SARS-CoV-2. Treatment resulted in a dose-dependent decrease in virus replication, achieving a $69.3 \%$ and $95.8 \%$ reduction of plaquing efficiency and viral copy

168 number with $30 \mu \mathrm{M}$ stenoparib, measured by plaque assay and RT-qPCR, respectively, compared to untreated controls ( $\mathrm{t}=7.982$ and 12.82, $\mathrm{P}=0.0002$ for both) (Fig. 4A and Fig. 4B). 
may target one or several intracellular growth stages, including virus entry (camostat mesylate,

172 hydroxychloroquine), endosomal processing (hydroxychloroquine, rapamycin), translation and RNA processing (lopinavir), and transcription and replication (remdesivir) $(1,11,30)$. By

174 altering the time of addition (TOA) and duration of treatment in vitro, we can discern whether a drug affects virus entry, intracellular growth, or both. TOA experiments were conducted using

176 the viral plaque assay with NL63 as a surrogate for SARS-CoV-2. RT-qPCR was performed in parallel to measure viral loads. We used remdesivir as a reference inhibitor, since its mechanism,

178 target and dosage range are known (31). Experiments to determine the lifecycle stages affected by stenoparib were performed as follows: a) to ascertain the effect on virus entry, cells were

180 transiently exposed to compounds starting $1 \mathrm{~h}$ before infection, and ending $1 \mathrm{~h}$ after infection; b) for effects on post-entry events, including transcription, processing, translation or replication, 182 compounds were added $1 \mathrm{~h}$ after infection, when a number of virions would have already entered cells, and treatment was continued until the experimental endpoint at $120 \mathrm{~h}$; c) to examine the 184 maximum achievable effect of the compounds, a full-time assay was performed. Treatment was initiated simultaneously with virus infection and continued until the $120 \mathrm{~h}$ endpoint (see

186 Methods for a detailed description).

As shown in Fig. 5A, the antiviral activity of stenoparib is most notable when added 188 post-infection. The $60 \mu \mathrm{M}$ stenoparib dose achieved complete inhibition of NL63 plaquing, with no detectable (N/D) plaques following post-entry treatment compared to untreated cells

$190(\mathrm{P}<0.0001)$. This is on par with the effect of $4 \mu \mathrm{M}$ remdesivir, which also eliminated plaque formation. Likewise, assay results for the full-time treatment were comparable between 192 stenoparib and remdesivir, with $88.4 \%$ reduction in plaque efficiency for stenoparib $(\mathrm{t}=5.582$, 
$\mathrm{P}=0.0051$ ), and full inhibition for remdesivir vs. untreated cells. This is consistent with our

194 results from $\mathrm{RT}$-qPCR, where stenoparib produced $98.7 \%(\mathrm{t}=9.988, \mathrm{P}=0.0099)$ and $95.5 \%$ $(\mathrm{t}=9.663, \mathrm{P}=0.0105)$ inhibition vs. untreated controls for post-entry and full-time drug exposure, and also comparable to the activity of remdesivir. These data are in line with those reported previously for the CVL218 PARP inhibitor and remdesivir (15).

With the plaque assay, we noticed a $16.5 \%$ reduction in plaque formation following transient treatment with stenoparib early in the infection time course (i.e. 'Entry'; Fig. 5A). This

200 effect was not markedly different than the results recorded for remdesivir $(-27.8 \% ; \mathrm{t}=1.919$, $\mathrm{P}=0.1275$ ). Inhibition of virus entry is not expected for remdesivir since its activity is specific to blocking of RNA replication $(31,32)$, which is a mid-late event in the viral lifecycle. In contrast, our results from RT-qPCR strongly support a specific effect for stenoparib on inhibiting virus

204 entry, where a $37.9 \%$ reduction in viral load is observed in the entry assay compared to just a 3.1\% reduction for remdesivir $(\mathrm{t}=4.352, \mathrm{P}=0.0121)$ (Fig. 5B). Effects on viral entry are

206 consistent with the predicted activity of stenoparib on processes involved in early coronavirus infection events (see Discussion). Taken as a whole, these observations suggest that stenoparib may affect multiple targets that play roles in the early and late stages of coronavirus intracellular multiplication.

The combination of stenoparib and remdesivir strongly inhibits NL63. Combination

drug therapies are widely used for the treatment for some of the worst human diseases, including

212 cancer (33), HIV/AIDS (34), and multidrug-resistant tuberculosis (35). The strategy of combination therapy seeks to increase the beneficial effects of multiple drugs, lower their doses

214 to reduce adverse effects, and minimize the induction of resistance (36). Generally, the activity of a drug combination is considered additive when the combined effect of two drugs is 
216 equivalent to their individual doses, while if the effect is less than additive, the combination is considered antagonistic. Synergy occurs when the combined effect is greater than the additive

218 effect (36). Combinations of two or more drugs may lead to a synergistic effect by combining different mechanisms of action (MOA). Examples of synergistic combinations of drugs with

220 distinct MOAs include streptomycin-penicillin (37), trimethoprim-sulfa drugs (Co-trimoxazole) (38), and $\beta$-lactam/ $\beta$-lactamase inhibitor combinations such as amoxicillin-clavulanate (39)

222 against bacterial infections.

Based on the fact that stenoparib and remdesivir inhibit coronavirus by distinct MOAs

$224(31,32,40)$, we approximated the half maximal effective concentration $\left(\mathrm{EC}_{50}\right)$ of stenoparib and remdesivir as $25.5 \mu \mathrm{M}$ and $0.46 \mu \mathrm{M}$ using the NL63 virus and plaque assays. Calculations were

226 aided by the online calculator from AAT Bioquest ("Quest Graph ${ }^{\mathrm{TM}}$ EC50 Calculator." $A A T$ Bioquest, Inc, 26 Oct. 2020, https://www.aatbio.com/tools/ec50-calculator). We hypothesized

228 that a combination of stenoparib and remdesivir would be more potent than the individual compounds. To test this, we combined a range of doses of stenoparib with $0.5 \mu \mathrm{M}$ remdesivir 230 and tested these for activity against NL63.

As shown in Fig. 6, complete inhibition of NL63 plaque formation was achieved with 60 $232 \mu \mathrm{M}$ stenoparib, in line with our earlier results with SARS-CoV-2 and Calu-3 cells (Fig. 3). Complete inhibition was also achieved with $1.0 \mu \mathrm{M}$ remdesivir. However, a combination of 10 $234 \mu \mathrm{M}$ stenoparib and $0.5 \mu \mathrm{M}$ remdesivir was more effective than either compound alone at these doses, achieving $90.7 \%$ inhibition for the combination, vs. $18.5 \%$ inhibition for $10 \mu \mathrm{M}$

236 stenoparib, and $65.6 \%$ for $0.5 \mu \mathrm{M}$ remdesivir, suggesting at least additive effects when the drugs are combined. Notably, the stenoparib dose $(10 \mu \mathrm{M})$ used in the combination is far below the 
bioRxiv preprint doi: https://doi.org/10.1101/2020.11.12.380394; this version posted November 16,2020 . The copyright holder for this preprint (which was not certified by peer review) is the author/funder, who has granted bioRxiv a license to display the preprint in perpetuity. It is made available under aCC-BY-NC-ND 4.0 International license.

238 compound's $\mathrm{EC}_{50}$ of $25.5 \mu \mathrm{M}$. Altogether, these results support investigating the use of stenoparib and remdesivir as a combinatorial therapy for SARS-family coronavirus infections. 


\section{Discussion}

Prior to the emergence of COVID-19, attempts to identify inhibitors of coronavirus were mainly focused on SARS- and MERS-CoVs. The recent efforts to develop COVID-19 therapeutics spans the gamut from new drug discovery to repurposing existing drugs. There are some excellent reviews on the subject $(17,41)$. Here, we focus on the compound stenoparib,

246 formerly known as $2 \mathrm{X}-121$, an inhibitor of the cellular enzyme PARP-1/2. Stenoparib is thought to inhibit SARS-CoV-2 by multiple mechanisms, predominately by inhibiting of ADP-

248 ribosylation of proteins required for virus replication and assembly (42). ADP-ribosylation is a conserved, post-translational modification that is key for proper formation of the coronavirus

250 nucleocapsid, and inhibition can negatively affect packaging of the viral genome and virion stability. Specific targets of ADP-ribosylation include viral nsp3 protein, which is essential for

252 virulence and a component of the replication/transcription complex (RTC) $(43,44)$. Moreover, PARP inhibitors may exert additional protective effects at the host and cellular levels by

254 reducing depletion of NAD+ and ATP that leads to cell necrosis (40), as well as decreasing the pro-inflammatory NF-kB-triggered cytokine storm that can damage host organs (45). It has also

256 been suggested that PARP inhibitors enhance the degradation of the host type I interferon receptor (IFN-1R), which would also have a modulatory effect on the host inflammatory 258 response (46).

In this study, inhibition of SARS-family coronaviruses by stenoparib in vitro is likely due

260 to interference with multiple stages of the virus lifecycle. Consistent with its predicted mechanism, stenoparib is effective when introduced post-infection. Additionally, we noted an

262 association between stenoparib treatment and decreased virus counts soon after infection. This may reflect activity against multiple targets, including those involved in promoting virus entry. 
264 Stenoparib interference with the activity of tankyrase and $\mathrm{Wnt} / \beta$-catenin signaling can downregulate expression of the ACE2 receptor, leading to a decrease in the number of viruses

266 that can enter the cell, which is consistent with effects on virus entry and with our observations. In contrast, inhibition by remdesivir was predominately on post-entry events - its effect on virus 268 entry was minimal at best, which is in line with its specific MOA of targeting the virus replication machinery. Overall, our observations imply multiple mechanisms for stenoparib,

270 including impeding of viral entry and intracellular growth via modifications of multiple viral and host proteins.

Other human coronaviruses that utilize ACE2 for binding and entry may be suitable as surrogate platforms for the study of SARS-CoV-2 in vitro, so long as they can be propagated in

274 the laboratory and are able to elicit cellular infection phenotypes that can be quantitatively measured. We show that the human seasonal coronavirus NL63, which can cause a cold-like 276 illness in humans (26), is such an example. Like SARS-CoV-2 and SARS-CoV, NL63 is internalized following the binding of viral S-complex proteins to the ACE2 receptor $(28,47-49)$.

278 According to our observations, NL63 is susceptible to inhibition by compounds that affect SARS-CoV-2, including remdesivir, the protease inhibitors camostat mesylate and E64d, and 280 stenoparib, the subject of this study.

In light of the in vitro cytotoxic effects of stenoparib, we were unable to test it in Vero E6 282 cells against SARS-CoV-2 at doses exceeding $30 \mu \mathrm{M}$. Stenoparib was developed as a cytotoxic drug for cancer treatment (14), so it is not surprising that it showed dose-dependent cytotoxicity 284 against rapidly-dividing Vero E6 cells. PARP inhibitors typically express their lethality after several replication cycles (50). The susceptibility of Vero E6 cells to stenoparib toxicity may be 286 linked to its fast-growing phenotype, since two replication cycles can be achieved in as little as 
48 h. Although LLC-MK2 cells, which are utilized for propagation and testing of NL63 are substantially more resistant to stenoparib, their susceptibility to SARS-CoV-2 infection is suboptimal. We were thus presented with a conundrum in how to test high doses of stenoparib against SARS-CoV-2 to assess its maximum activity. This was addressed through the use of the Calu-3 human lung carcinoma cell line to model SARS-CoV-2 infections. Our results confirm the suitability of Calu-3 as a host for SARS-CoV-2 and its high degree of resistance to stenoparib toxicity. This characteristic of Calu-3 cells was predicted in silico using a method previously

294 employed on clinical tumor biopsies (22), and experimentally validated in this study. Infection of Calu-3 monolayers with SARS-CoV-2 formed large, clearly visible plaques, and in this regard, 296 the performance of Calu-3 surpassed Vero E6. A notable characteristic of Calu-3 is its slow growth properties, which may coincide with a general degree of resistance to compounds that 298 target essential cellular pathways and are toxic to more rapidly dividing cells.

A promising drug to emerge from COVID therapeutic trials is the nucleoside analog 300 remdesivir, which shows activity against phylogenetically diverse viruses including Ebola, Nipah, respiratory syncytial virus (RSV), and coronaviruses such as SARS- and MERS-CoV

302 (51), SARS-CoV-2 (31) and, as reported here, the seasonal human HCoV-NL63. Reviews on the MOA of remdesivir have been published $(17,41,51)$. After entering the cell, remdesivir is triple 304 phosphorylated to form remdesivir-triphosphate, and this structure is thought to inhibit RNA polymerase, resulting in chain termination. While the precise molecular mechanism is not clear 306 (51), the $\mathrm{EC}_{50}$ of remdesivir has been reported to be $0.77 \mu \mathrm{M}$ for SARS-CoV-2 (31), which is in line with our measurement of $0.54 \mu \mathrm{M}$ for SARS-CoV-2, and comparable to our experimentally308 determined $\mathrm{EC}_{50}$ of $0.46 \mu \mathrm{M}$ against NL63. 
While remdesivir inhibits the viral replicon, our data support multiple targets for

310 stenoparib. Moreover, stenoparib and remdesivir may be a potent combination at inhibiting SARS-family coronaviruses inside cells. A mixture of $10 \mu \mathrm{M}$ stenoparib and $0.5 \mu \mathrm{M}$ remdesivir

312 was more successful at inhibiting the NL63 virus than either compound alone at these doses.

Considering their distinct mechanisms and high potency, a combination of remdesivir and

314 stenoparib is likely to produce a synergistic effect on additional SARS-family coronaviruses, including SARS-CoV-2. Studies involving this combination in susceptible COVID-19 animal

316 models are in line for efficacy testing. 


\section{Materials and Methods}

The antiviral activity of stenoparib in vitro was assessed against the novel coronavirus

SARS-CoV-2 isolate USA-WA1/2020 (BEI Resources, NIAID, NIH: SARS-Related

322 Coronavirus 2, Isolate USA-WA1/2020, NR-52281) and human coronavirus strain HCoV_NL63

(BEI Resources, NIAID, NIH NR-470). We used Vero E6 (ATCC CRL-1586) and Calu-3 cells

324 (ATCC HTB-55) from the American Type Culture Collection (ATCC, Manassas, VA, USA) in

EMEM (Eagle's Minimum Essential Medium) supplemented with $2 \%$ or $10 \%$ fetal bovine serum

326 (FBS), $100 \mathrm{U} / \mathrm{mL}$ penicillin, $100 \mu \mathrm{g} / \mathrm{mL}$ streptomycin 'pen-strep', $0.01 \mathrm{M}$ HEPES, $1 \mathrm{mM}$

sodium pyruvate, 1x non-essential amino acids solution (SH3023801, Thermo Fisher), and $2 \mathrm{mM}$

328 L-glutamine, for the propagation and experimentation with SARS-CoV-2. LLC-MK2 cells

(ATCC CCL-7), maintained in Medium 199 (M4530, Millipore Sigma) supplemented with FBS

330 and pen-strep, were used for the experiments with the NL63 coronavirus. Inhibition of viral replication was assessed using reverse-transcription quantitative real-time PCR (RT-qPCR) to

332 measure the number of virions released into the cellular supernatant.

Plaque assays. 6-well plates (CLS3516, Millipore Sigma) were seeded with $\sim 3.0 \times 10^{\wedge} 5$

334 cells/well and incubated for $48-72 \mathrm{~h}$ at $37^{\circ} \mathrm{C}$ in $5 \% \mathrm{CO}_{2}$ until $80-90 \%$ confluency was reached.

Calu-3 cells were incubated for $>10$ days to achieve $80-90 \%$ confluency. Prior to infection the

336 media was replaced with fresh media containing 2.0\% FBS with varying concentrations of

stenoparib as appropriate for each experiment (see results) and infected with coronavirus (SARS-

338 CoV-2 or NL63) at an MOI of 0.013 for SARs-CoV-2 and 0.003 for NL63. Media was then replaced with a 1 X Dulbecco's MEM (DMEM - Millipore Sigma) / 1.2\% low-melting agarose

340 (Bio-Rad) overlay containing the appropriate drug concentration for each experiment. This was allowed to solidify at room temperature for 15 minutes, and incubated for $120 \mathrm{~h}$ at $37^{\circ} \mathrm{C}$ in a $5 \%$ 
$342 \mathrm{CO} 2$ atmosphere. A cocktail of the protease inhibitors camostat mesylate and E64d (C/E) was a control for all experiments (21). SARS-CoV-2 manipulations were conducted in a BSL-3

344 facility. $2.0 \mathrm{ml}$ of $4 \%$ paraformaldehyde was added to each overlay for 30 minutes, followed by staining with $1.0 \%$ crystal violet, removal of the overlay, and a triple rinse with PBS. Plaque

346 forming units (pfu) were counted, averaged, and normalized to the untreated control group. Each run contained three biological replicates and was conducted a minimum of two times. Standard

348 deviation was calculated using the variation of averaged counts among all runs. Values were plotted using GraphPad Prism version 8.0.0 for Windows (GraphPad Software) and annotated 350 using Adobe Illustrator (Adobe Systems Incorporated). Statistical significance was determined using a parametric unpaired t-test in GraphPad Prism version 8.0.0.

RT-qPCR: Infection and viral RNA extraction. 12-well plates (CLS3513, Millipore

Sigma) were seeded with $\sim 1.0 \times 10^{\wedge} 5$ cells/well and incubated until $80-90 \%$ confluency was

354 reached. Growth media was replaced and infected with coronavirus (SARS-CoV-2 or NL63) at an MOI of 0.04 for SARs-CoV-2 and 0.01 for NL63 for up to $120 \mathrm{~h}$ at $37^{\circ} \mathrm{C}$ in $5 \% \mathrm{CO} 2$

356 atmosphere. $\mathrm{C} / \mathrm{E}$ was used as a control inhibitor for all experiments. Each run contained two biological replicates and was conducted three times. $400 \mu \mathrm{L}$ of supernatant was harvested at $48 \mathrm{~h}$

358 for SARS-CoV-2, $120 \mathrm{~h}$ for NL63. RNA was extracted using Invitrogen Pure-Link RNA kits (Thermo Fisher) according to their recommendations. assays were designed for the SARS-CoV-2 or the NL63 coronaviruses. For NL63, the reference 362 genome (NC_005831) was divided into 200 nucleotide fragments, which were aligned against a set of 2,771 coronavirus genomes with BLAT v36.2 (52) in conjunction with LS-BSR v1.2.2 
genomes, and a BSR value $<0.4$ in all other coronavirus genomes. A total of 10 fragments were

highly specific to all NL63 genomes. Primers and probes were identified using Primer3 v2.3.6

(55). A similar process was conducted for SARS-CoV-2 assay design, except the

GCF_009858895.2 reference genome was used. A total of 4 fragments were unique to 64 distinct SARS-CoV-2 genomes. A probe was designed targeting the spike (S) protein furin cleavage site with Primer3.

The SARS-CoV-2 qPCR amplified a 125 bp region of the S protein using forward primer CoV2-S_19F (5' -GCTGAACATGTCAACAACTC-3') and reverse primer CoV2-S_143R (5' GCAATGATGGATTGACTAGC-3') with MGB TaqMan probe CoV2-S_93FP (5'-

ACTAATTCTCCTCGGCGGGC-3') labeled with FAM dye, which was designed based off the SARS-CoV-2 genome GCF_009858895.2 (GenBank: MN908947.3), while the NL63 qPCR

376 amplified a $191 \mathrm{bp}$ region of a membrane protein (GenBank: YP_003770.1) using forward primer NL63_10F (5'-TGGTCGCTCTGTTAATGAAA-3') and reverse primer NL63_200R (5'AAATTTCTTCCTAGCAGCTC-3') with MGB TaqMan probe NL63_102RP (5'CCCTCCTGAGAGGCAACACC-3'), labeled with a VIC dye, which was based off the 380 HCoV_NL63 genome (GenBank: MN306040.1).

RT-qPCR: Reverse transcription and PCR amplification. We initially used a two-step 382 method where viral RNA was converted into cDNA using Invitrogen SuperScript IV VILO Master Mix (11766500, Thermo Fisher) in 96-well format (18021-014, Thermo Fisher); in a 384 SimpliAmp ${ }^{\circledR}$ thermocycler (Applied Biosystems). $1 \mu \mathrm{L}$ of template cDNA was then subjected to qPCR in $10 \mu \mathrm{L}$ reactions containing 1x TaqMan Universal Master Mix II (w/o AmpERASE $386 \mathrm{UNG}$ ), with $0.2 \mu \mathrm{M}$ of each forward and reverse primer and $0.1 \mu \mathrm{M}$ of probe for the SARSCoV-2 qPCR and $0.25 \mu \mathrm{M}$ of each forward and reverse primer and $0.125 \mu \mathrm{M}$ of probe for the 
388 NL63 qPCR). Amplification was performed in triplicate using either a QuantStudio 7 flex or QuantStudio $12 \mathrm{~K}$ (Applied Biosystems) utilizing: $10^{\prime}$ at $95^{\circ} \mathrm{C}$, then $40 \mathrm{X}$ at $95^{\circ} \mathrm{C} 15^{\prime \prime}, 60^{\circ} \mathrm{C}$ for

3901 '. Another approach employed a one-step procedure in which viral RNA was converted to cDNA using the TaqMan primers, followed by qPCR (4x Reliance One-Step Multiplex RT-

392 qPCR Supermix) with the same primers, probes, and concentrations as for the two-step approach. Triplicate reactions were performed using QuantStudio under the following conditions: $50^{\circ} \mathrm{C}$ for $39410^{\prime} ; 95^{\circ} \mathrm{C}, 10^{\prime} ; 40$ cycles of $95^{\circ} \mathrm{C} 10^{\prime \prime}$ and $60^{\circ} \mathrm{C} 30^{\prime}$. Positive amplification and non-template controls were included on every run.

RT-qPCR: Data analysis. Synthetic double-stranded DNA fragments were generated (gBlocks Gene Fragments, Integrated DNA Technologies) as qPCR controls, and contained 398 amplification primers for either SARS-CoV-2 or NL63 targets, and were elongated to $200 \mathrm{bp}$. These gBlocks were resuspended according to the manufacturer's protocol and quantified using a 400 Qubit 4 fluorometer with a dsDNA HS assay kit (Q32851 Thermo Fisher), then normalized to $10^{\wedge} 8$ copies per $\mu \mathrm{L}$. Using serial dilution, we were able to extrapolate viral copy number in each 402 of the experimental samples. Based on these standards, the QuantStudio instrument software generated a curve to quantify sample reactions. The calculated quantities for each sample were

404 averaged, and the standard deviation was calculated among reactions. Values for the experimental replicates and the standard deviations among experimental runs were averaged, and 406 then normalized to the untreated control group to obtain percent inhibition values. These were plotted using GraphPad Prism version 8.0.0 for Windows and annotations were added using 408 Adobe Illustrator. Where appropriate, statistical significance was determined using a parametric unpaired t-test in GraphPad Prism version 8.0.0. 
Nonradioactive Cytotoxicity Assay kit (G1780) in $50 \mu \mathrm{L}$ reactions according to the

412 manufacturer's protocol. The absorbance at $490 \mathrm{~nm}$ (A490) was measured using a BioTeK Synergy $^{\text {TM }}$ HT plate reader model \# 7091000. Relative cytotoxicity was calculated by dividing

414 the experimental LDH release as measured at 490nm by the maximum LDH release control multiplied by 100 .

416 Time of addition experiments. For the full-time experiments, virus, drug and cells were incubated for $1 \mathrm{~h}$. Media was then replaced with fresh media containing the drug. Entry

418 experiments were pretreated with drug for $1 \mathrm{~h}$ and then infected with virus for an additional hour, followed by media replacement that lacked drug. Post-entry experiments utilized cells that were

420 infected with virus for $1 \mathrm{~h}$, and media was replaced with fresh media containing the drug. Statistical significance was determined using a parametric unpaired t-test in GraphPad Prism 422 version 8.0.0.

Stenoparib in combination with remdesivir. We performed plaque assays, and used

424 these data to estimate the $\mathrm{EC}_{50}$ of stenoparib and remdesivir (329511, MedKoo Biosciences, Morrisville, NC, USA) against NL63 (both drugs) and SARS-CoV-2 (remdesivir only) in LLC-

426 MK2 and Vero E6 cells according to results from at least two experimental runs. The $\mathrm{EC}_{50}$ values were approximated with the aid of the online calculator from AAT Bioquest ("Quest

428 Graph ${ }^{\mathrm{TM}}$ EC50 Calculator." AAT Bioquest, Inc, 26 Oct. 2020, https://www.aatbio.com/tools/ec50-calculator). 
bioRxiv preprint doi: https://doi.org/10.1101/2020.11.12 380394 this version posted November 16,2020 . The copyright holder for this preprint

(which was not certified by peer review) is the author/funder, who has granted bioRxiv a license to display the preprint in perpetuity. It is made available under aCC-BY-NC-ND 4.0 International license.

\section{Acknowledgments}

432 This research was supported by a grant from The Flinn Foundation and continuing support of The Cowden Endowment for Microbiology. Core experiments were supported by service fees

434 paid by Allarity Therapeutics.

\section{Conflict of Interest Statement}

SK is employed by and holds a financial interest in Allarity Therapeutics, which stands to

438 potentially benefit from these results. 


\section{References}

1. Hu B, Guo H, Zhou P, Shi ZL. 2020. Characteristics of SARS-CoV-2 and COVID-19. Nature Reviews Microbiology doi:10.1038/s41579-020-00459-7.

2. Wu ZY, McGoogan JM. 2020. Characteristics of and Important Lessons From the Coronavirus Disease 2019 (COVID-19) Outbreak in China Summary of a Report of 72 314 Cases From the Chinese Center for Disease Control and Prevention. Jama-Journal of the American Medical Association 323:1239-1242.

3. Liu Y, Mao B, Liang S, Yang JW, Lu HW, Chai YH, Wang L, Zhang L, Li QH, Zhao L, He Y, Gu XL, Ji XB, Li L, Jie ZJ, Li Q, Li XY, Lu HZ, Zhang WH, Song YL, Qu JM, Xu JF, Treatment SC. 2020. Association between age and clinical characteristics and outcomes of COVID-19. European Respiratory Journal 55.

4. Wu C, Chen X, Cai Y. 2020. Risk factors associated with acute respiratory distress syndrome and death in patients with coronavirus disease 2019 pneumonia in Wuhan, China (vol 180, pg 934, 2020). Jama Internal Medicine 180:1031-1031.

5. Guan W, Ni Z, Hu Y, Liang W, Ou C, He J, Liu L, Shan H, Lei C, Hui DSC, Du B, Li L, Zeng G, Yuen KY, Chen R, Tang C, Wang T, Chen P, Xiang J, Li S, Wang JL, Liang Z, Peng Y, Wei L, Liu Y, Hu YH, Peng P, Wang JM, Liu J, Chen Z, Li G, Zheng Z, Qiu S, Luo J, Ye C, Zhu S, Zhong N, Grp CMTE. 2020. Clinical Characteristics of Coronavirus Disease 2019 in China. New England Journal of Medicine 382:1708-1720.

6. Dong E, Du H, Gardner L. 2020. An interactive web-based dashboard to track COVID-19 in real time. Lancet Infect Dis 20:533-534.

7. Impact JHCfC. 2020. Coronavirus Resource Center - COVID Tracker. https://www.arcgis.com/apps/opsdashboard/index.htm|\#/409af567637846e3b5d4182fcd $779 \mathrm{bea}$. Accessed

8. Team IC-F. 2020. Modeling COVID-19 scenarios for the United States. Nat Med doi:10.1038/s41591-020-1132-9.

468 9. Rabi FA, Al Zoubi MS, Kasasbeh GA, Salameh DM, AI-Nasser AD. 2020. SARS-CoV-2 and Coronavirus Disease 2019: What We Know So Far. Pathogens 9.

470 10. Hoffmann M, Kleine-Weber H, Schroeder S, Kruger N, Herrler T, Erichsen S, Schiergens TS, Herrler G, Wu NH, Nitsche A, Muller MA, Drosten C, Pohlmann S. 2020. SARSCoV-2 Cell Entry Depends on ACE2 and TMPRSS2 and Is Blocked by a Clinically Proven Protease Inhibitor. Cell 181:271-280 e8.

474 11. Poduri R, Joshi G, Jagadeesh G. 2020. Drugs targeting various stages of the SARSCoV-2 life cycle: Exploring promising drugs for the treatment of Covid-19. Cell Signal 74:109721.

12. Astuti I, Ysrafil. 2020. Severe Acute Respiratory Syndrome Coronavirus 2 (SARS-CoV2): An overview of viral structure and host response. Diabetes Metab Syndr 14:407-412.

13. Dziadkowiec KN, Gasiorowska E, Nowak-Markwitz E, Jankowska A. 2016. PARP

482 14. McGonigle S, Chen ZH, Wu JY, Chang P, Kolber-Simonds D, Ackermann K, Twine NC, Shie JL, Miu JZT, Huang KC, Moniz GA, Nomoto K. 2015. E7449: A dual inhibitor of PARP1/2 and tankyrase $1 / 2$ inhibits growth of DNA repair deficient tumors and antagonizes Wnt signaling. Oncotarget 6:41307-41323.

15. Ge Y, Tian T, Huang S, Wan F, Li J, Li S, Yang H, Hong L, Wu N, Yuan E, Cheng L, Lei Y, Shu H, Feng X, Jiang Z, Chi Y, Guo X, Cui L, Xiao L, Li Z, Yang C, Miao Z, Tang H, 
framework discovered a potential therapeutic agent targeting COVID-19. bioRxiv doi:10.1101/2020.03.11.986836:2020.03.11.986836.

16. Pushpakom S, lorio F, Eyers PA, Escott KJ, Hopper S, Wells A, Doig A, Guilliams T, Latimer J, McNamee C, Norris A, Sanseau P, Cavalla D, Pirmohamed M. 2018. Drug repurposing: progress, challenges and recommendations. Nat Rev Drug Discov doi:10.1038/nrd.2018.168.

17. Saha RP, Sharma AR, Singh MK, Samanta S, Bhakta S, Mandal S, Bhattacharya M, Lee SS, Chakraborty C. 2020. Repurposing Drugs, Ongoing Vaccine, and New Therapeutic Development Initiatives Against COVID-19. Front Pharmacol 11:1258.

498 18. Zhou YD, Hou Y, Shen JY, Huang Y, Martin W, Cheng FX. 2020. Network-based drug repurposing for novel coronavirus 2019-nCoV/SARS-CoV-2. Cell Discovery 6.

500 19. Qinfen Z, Jinming C, Xiaojun $H$, Huanying $Z$, Jicheng $H$, Ling $F$, Kunpeng L, Jingqiang $Z$. 2004. The life cycle of SARS coronavirus in Vero E6 cells. J Med Virol 73:332-7.

502 20. Ogando NS, Dalebout TJ, Zevenhoven-Dobbe JC, Limpens R, van der Meer Y, Caly L, Druce J, de Vries JJC, Kikkert M, Barcena M, Sidorov I, Snijder EJ. 2020. SARScoronavirus-2 replication in Vero E6 cells: replication kinetics, rapid adaptation and cytopathology. J Gen Virol 101:925-940.

506 21. Li J, Zhan P, Liu X. 2020. Targeting the entry step of SARS-CoV-2: a promising therapeutic approach. Signal Transduct Target Ther 5:98.

508 22. Plummer R, Dua D, Cresti N, Drew Y, Stephens P, Foegh M, Knudsen S, Sachdev P, Mistry BM, Dixit V, McGonigle S, Hall N, Matijevic M, McGrath S, Sarker D. 2020. Firstin-human study of the PARP/tankyrase inhibitor E7449 in patients with advanced solid tumours and evaluation of a novel drug-response predictor. $\mathrm{Br} \mathrm{J}$ Cancer 123:525-533.

512 23. Chu H, Chan JF, Yuen TT, Shuai H, Yuan S, Wang Y, Hu B, Yip CC, Tsang JO, Huang $X$, Chai Y, Yang D, Hou Y, Chik KK, Zhang X, Fung AY, Tsoi HW, Cai JP, Chan WM, Ip JD, Chu AW, Zhou J, Lung DC, Kok KH, To KK, Tsang OT, Chan KH, Yuen KY. 2020. Comparative tropism, replication kinetics, and cell damage profiling of SARS-CoV-2 and SARS-CoV with implications for clinical manifestations, transmissibility, and laboratory studies of COVID-19: an observational study. Lancet Microbe 1:e14-e23.

518 24. Fogh J, Fogh JM, Orfeo T. 1977. One hundred and twenty-seven cultured human tumor cell lines producing tumors in nude mice. J Natl Cancer Inst 59:221-6.

520 25. Baer A, Kehn-Hall K. 2014. Viral concentration determination through plaque assays: using traditional and novel overlay systems. J Vis Exp doi:10.3791/52065:e52065.

522 26. van der Hoek L, Pyrc K, Berkhout B. 2006. Human coronavirus NL63, a new respiratory virus. FEMS Microbiol Rev 30:760-73.

524 27. Glowacka I, Bertram S, Herzog P, Pfefferle S, Steffen I, Muench MO, Simmons G, Hofmann H, Kuri T, Weber F, Eichler J, Drosten C, Pohlmann S. 2010. Differential downregulation of ACE2 by the spike proteins of severe acute respiratory syndrome coronavirus and human coronavirus NL63. J Virol 84:1198-205.

28. Li W, Sui J, Huang IC, Kuhn JH, Radoshitzky SR, Marasco WA, Choe H, Farzan M. 2007. The S proteins of human coronavirus NL63 and severe acute respiratory syndrome coronavirus bind overlapping regions of ACE2. Virology 367:367-74. senescence and cytokine storm with rapamycin to prevent severe progression in COVID-19. Clin Immunol 216:108464. (2019-nCoV) in vitro. Cell Res 30:269-271. 
540 32. Chang CK, Jeyachandran S, Hu NJ, Liu CL, Lin SY, Wang YS, Chang YM, Hou MH. 2016. Structure-based virtual screening and experimental validation of the discovery of inhibitors targeted towards the human coronavirus nucleocapsid protein. Mol Biosyst 12:59-66.

544 33. Bigioni M, Benzo A, Irrissuto C, Lopez G, Curatella B, Maggi CA, Manzini S, Crea A, Caroli S, Cubadda F, Binaschi M. 2008. Antitumour effect of combination treatment with

\section{Chemother Pharmacol 62:621-9.}

548 34. Casado JL, Banon S. 2015. Dutrebis (lamivudine and raltegravir) for use in combination with other antiretroviral products for the treatment of HIV-1 infection. Expert Rev Clin Pharmacol 8:709-18.

35. Caminero JA, Sotgiu G, Zumla A, Migliori GB. 2010. Best drug treatment for multidrugresistant and extensively drug-resistant tuberculosis. Lancet Infect Dis 10:621-9.

36. Garcia-Fuente A, Vazquez F, Vieitez JM, Garcia Alonso FJ, Martin JI, Ferrer J. 2018.

\section{6} CISNE: An accurate description of dose-effect and synergism in combination therapies. Sci Rep 8:4964.

37. Reynolds B, Rowley D. 1953. Synergism between streptomycin and penicillin. British journal of experimental pathology 34:651-655.

38. Nichols RJ, Sen S, Choo YJ, Beltrao P, Zietek M, Chaba R, Lee S, Kazmierczak KM, Lee KJ, Wong A, Shales M, Lovett S, Winkler ME, Krogan NJ, Typas A, Gross CA.

39. Yogev R, Melick C, Kabat WJ. 1981. In vitro and in vivo synergism between amoxicillin

40. Kouhpayeh S, Shariati L, Boshtam M, Rahimmanesh I, Mirian M, Zeinalian M, Salari-jazi A, Khanahmad N, Damavandi MS, Sadeghi P, Khanahmad H. 2020. The molecular story doi:10.20944/preprints202003.0346.v1.

41. Pillaiyar T, Meenakshisundaram S, Manickam M. 2020. Recent discovery and development of inhibitors targeting coronaviruses. Drug Discov Today 25:668-688.

572 43. Lei J, Kusov Y, Hilgenfeld R. 2018. Nsp3 of coronaviruses: Structures and functions of a large multi-domain protein. Antiviral Res 149:58-74.

574 44. Fehr AR, Athmer J, Channappanavar R, Phillips JM, Meyerholz DK, Perlman S. 2015. The nsp3 macrodomain promotes virulence in mice with coronavirus-induced

576 encephalitis. J Virol 89:1523-36.

45. Gharote MA. 2020. Role of poly (ADP) ribose polymerase-1 inhibition by nicotinamide as

580 46. Coperchini F, Chiovato L, Croce L, Magri F, Rotondi M. 2020. The cytokine storm in COVID-19: An overview of the involvement of the chemokine/chemokine-receptor system. Cytokine Growth Factor Rev 53:25-32.

47. Smith MK, Tusell S, Travanty EA, Berkhout B, van der Hoek L, Holmes KV. 2006. coronavirus NL63. Adv Exp Med Biol 581:285-8.

586 48. Pohlmann S, Gramberg T, Wegele A, Pyrc K, van der Hoek L, Berkhout B, Hofmann H. 2006. Interaction between the spike protein of human coronavirus NL63 and its cellular receptor ACE2. Adv Exp Med Biol 581:281-4.

49. $\quad$ Lin HX, Feng Y, Wong G, Wang L, Li B, Zhao X, Li Y, Smaill F, Zhang C. 2008. Identification of residues in the receptor-binding domain (RBD) of the spike protein of 
human coronavirus NL63 that are critical for the RBD-ACE2 receptor interaction. J Gen Virol 89:1015-1024.

50. Garnett MJ, Edelman EJ, Heidorn SJ, Greenman CD, Dastur A, Lau KW, Greninger P, Thompson IR, Luo X, Soares J, Liu Q, lorio F, Surdez D, Chen L, Milano RJ, Bignell GR, Tam AT, Davies H, Stevenson JA, Barthorpe S, Lutz SR, Kogera F, Lawrence K, McLaren-Douglas A, Mitropoulos X, Mironenko T, Thi H, Richardson L, Zhou W, Jewitt F, Zhang T, O'Brien P, Boisvert JL, Price S, Hur W, Yang W, Deng X, Butler A, Choi HG, Chang JW, Baselga J, Stamenkovic I, Engelman JA, Sharma SV, Delattre O, SaezRodriguez J, Gray NS, Settleman J, Futreal PA, Haber DA, et al. 2012. Systematic identification of genomic markers of drug sensitivity in cancer cells. Nature 483:570-5.

51. Saha A, Sharma AR, Bhattacharya M, Sharma G, Lee SS, Chakraborty C. 2020.

Know More. Arch Med Res 51:585-586.

604 52. Kent WJ. 2002. BLAT--the BLAST-like alignment tool. Genome Res 12:656-64.

53. Sahl JW, Caporaso JG, Rasko DA, Keim P. 2014. The large-scale blast score ratio (LS-

606 BSR) pipeline: a method to rapidly compare genetic content between bacterial genomes. PeerJ 2:e332.

608 54. Rasko DA, Myers GS, Ravel J. 2005. Visualization of comparative genomic analyses by BLAST score ratio. BMC Bioinformatics 6:2.

610 55. Rozen S, Skaletsky H. 2000. Primer3 on the WWW for general users and for biologist programmers. Methods Mol Biol 132:365-86. 


\section{Figures}

616 Fig. 1. Stenoparib exhibits dose-dependent inhibition of SARS-CoV-2 as measured by RTqPCR. RT-qPCR was performed on viral RNA collected from cell culture supernatants at $48 \mathrm{~h}$

618 post infection. Replicates within each run were averaged, and a total of three experiments were performed. Error bars were based on averaged standard deviations within runs. Cytotoxicity

620 against Vero E6 cells was determined at $48 \mathrm{~h}$ using the Promega ${ }^{\mathrm{TM}}$ CytoTox $96^{\mathrm{TM}}$ assay kit, and values represent the average of the two independent experiments (reported in Fig. 2A).

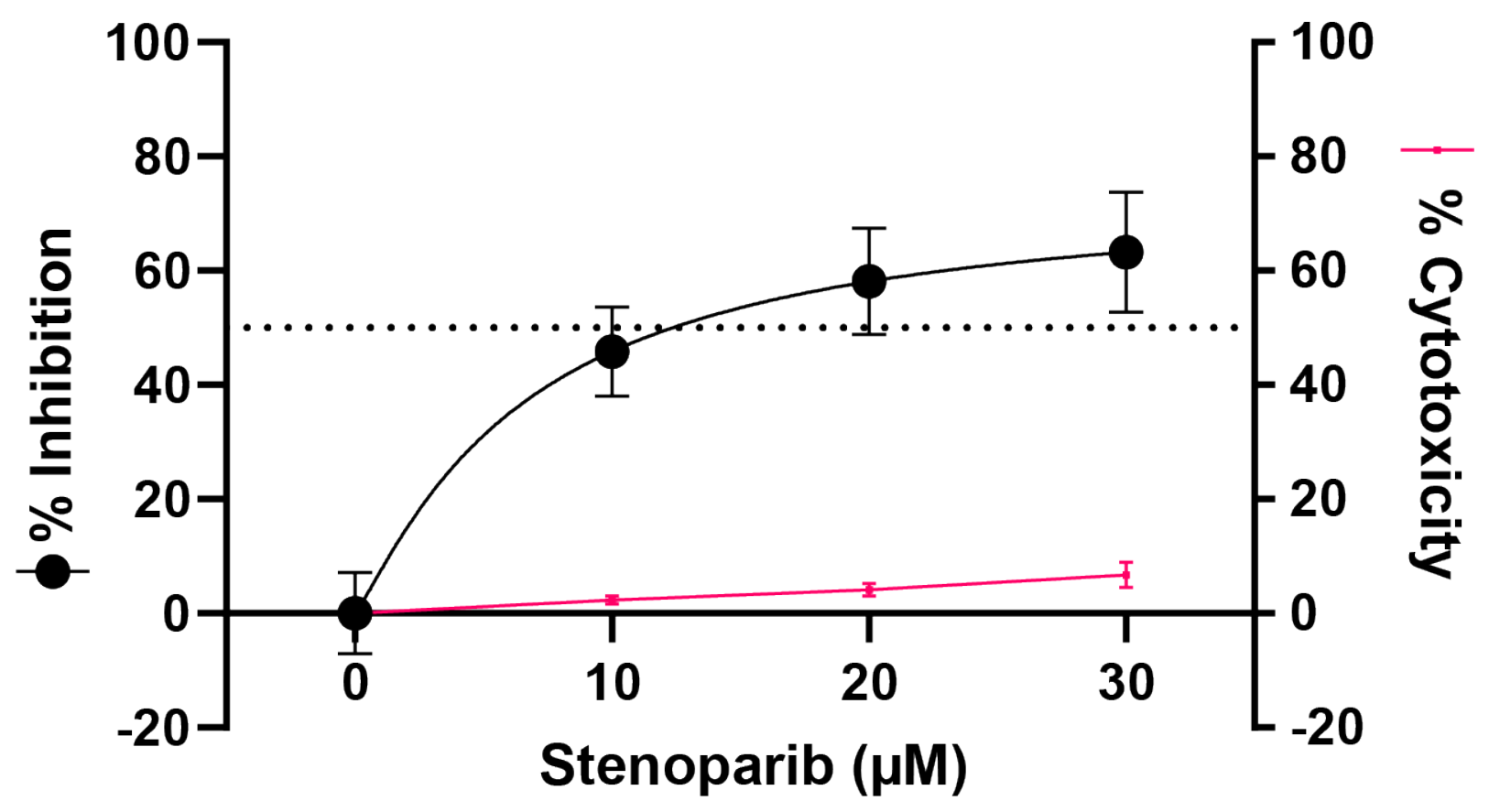


626 Fig. 2. Stenoparib is cytotoxic in Vero E6 cells at concentrations greater than $30 \mu \mathrm{M}$, but not in Calu-3 cells. Cytotoxicity was determined using the Promega ${ }^{\mathrm{TM}}$ CytoTox $96^{\mathrm{TM}}$ lactatedehydrogenase-release assay kit by harvesting culture media every $24 \mathrm{~h}$ up to $120 \mathrm{~h}$ post exposure. A) Vero E6 cells; B) Calu-3 cells, with 10, 20, 30, and $60 \mu \mathrm{M}$ of stenoparib.

630 Measurements were normalized to cells treated with 1.0\% Triton X-100 and compared to untreated controls. Biological replicates from two runs were averaged, and median values are

632 plotted. Results are representative of two experiments, and error bars are based on the standard deviation.
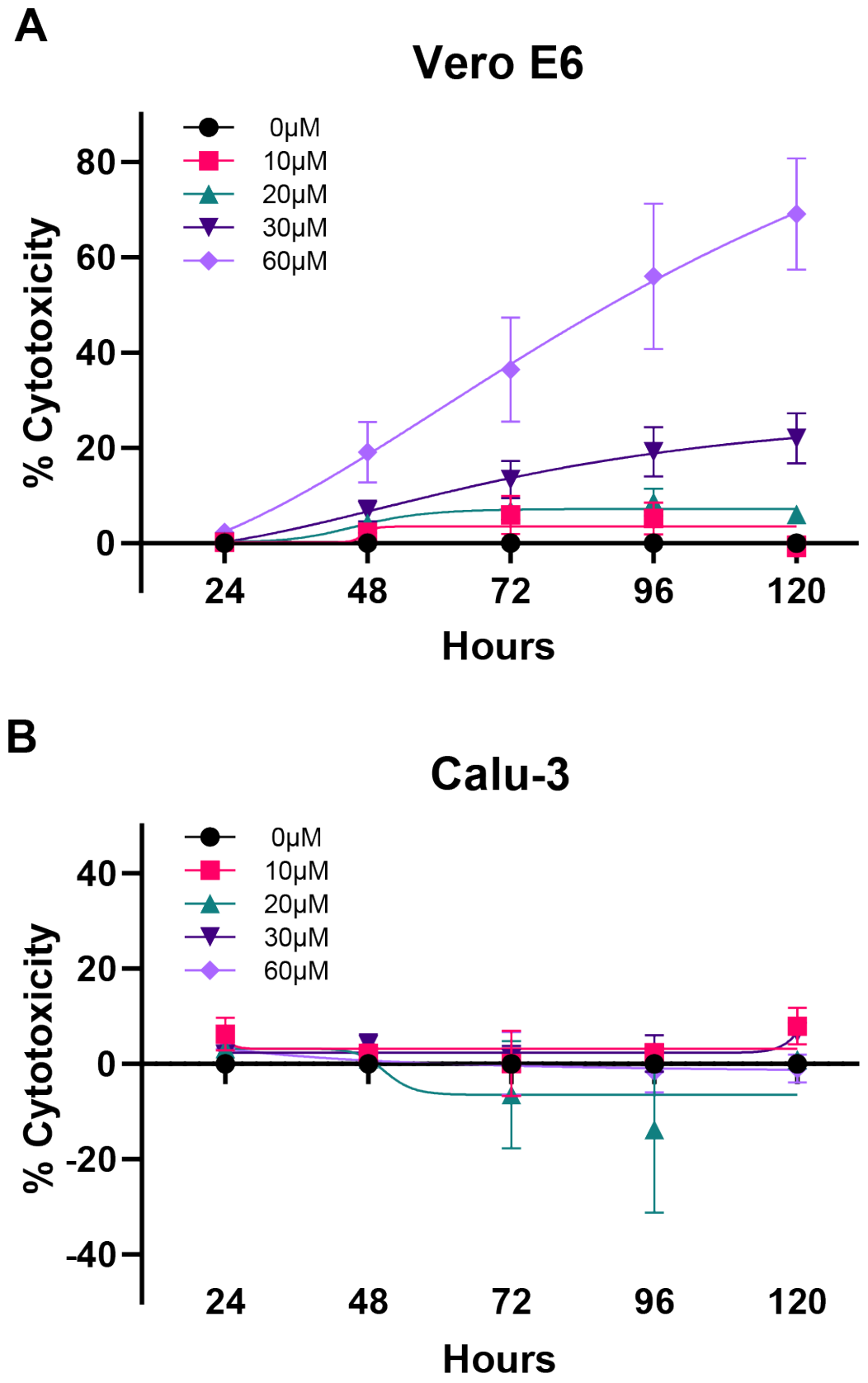
636 Fig. 3. Stenoparib exhibits dose-dependent inhibition of SARS-CoV-2 in Calu-3 cells. A) Plaque forming efficiency using SARS-CoV-2. Values are normalized as a percentage of

638 inhibition compared to infected, but untreated cells. Plaques were counted $120 \mathrm{~h}$ after infection, replicates from each run were averaged, and assays were performed three times. Error bars are

640 based on the standard deviation across all runs. B) RT-qPCR was performed on viral RNA collected from cell culture supernatants at $48 \mathrm{~h}$ post infection and replicate values within each

642 run were averaged; a total of three runs were performed. Error bars are based on averaged standard deviations within runs. Cytotoxicity against Calu-3 cells was determined at 48 and 120

$644 \mathrm{~h}$, as appropriate, using the Promega ${ }^{\mathrm{TM}}$ CytoTox $96^{\mathrm{TM}}$ assay kit, and values represent the average of the two independent experiments (reported in Fig. 2B).

A

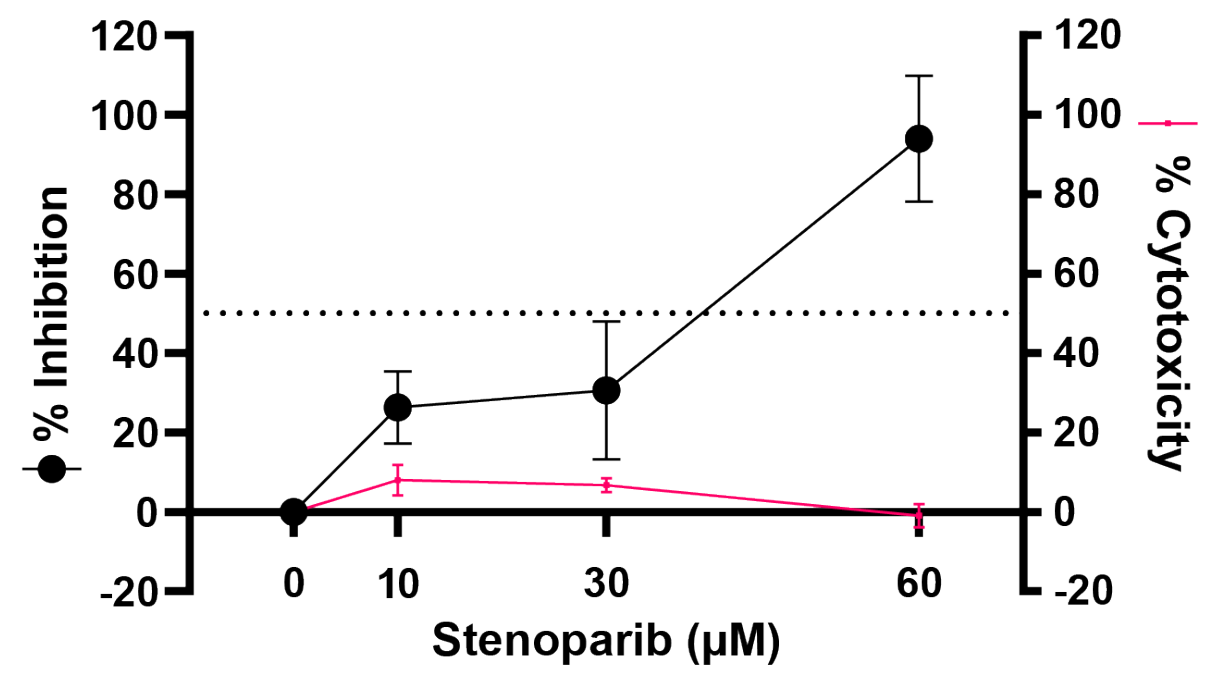

B

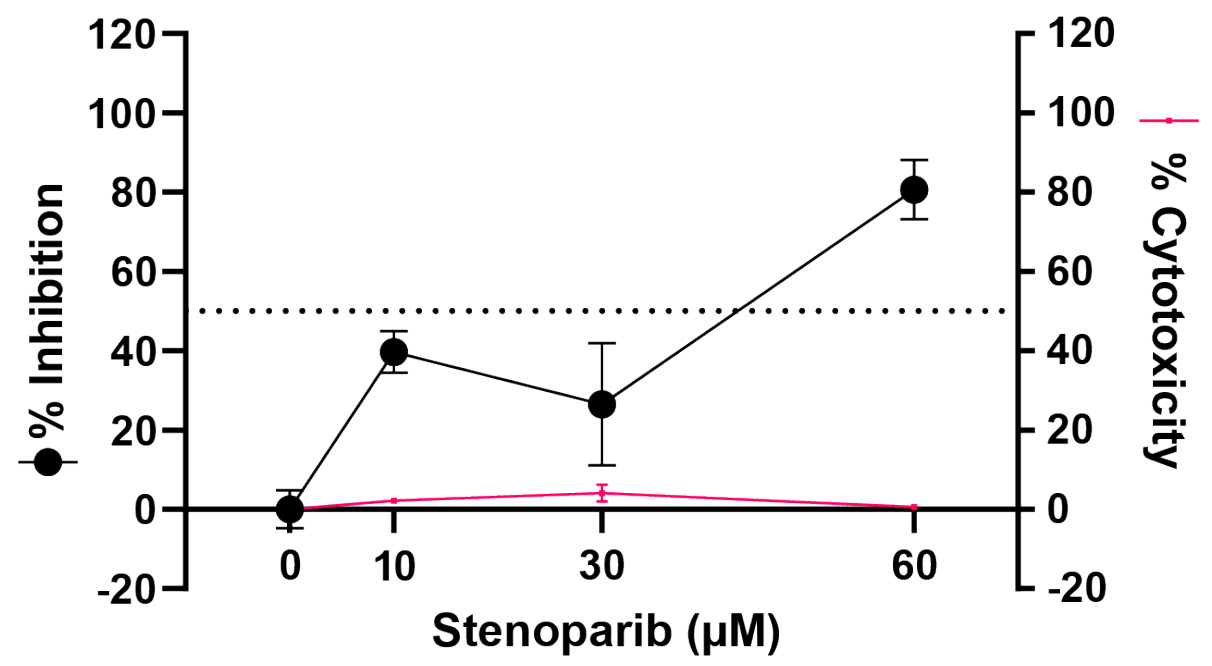


Fig. 4. Stenoparib exhibits dose-dependent inhibition of HCoV-NL63 in LLC-MK2 cells. A) Plaquing efficiency values are normalized as a percentage of inhibition compared to infected, but untreated cells. Plaques were counted $120 \mathrm{~h}$ after infection, and assays were performed three times. Error bars are based on the standard deviation across all runs. B) RT-qPCR was performed on viral RNA collected from cell culture media at $120 \mathrm{~h}$ post infection. Biological replicates

654 from each run were averaged, and three independent runs were performed. Error bars were based on averaged standard deviations within runs. Cytotoxicity against LLC-MK2 cells was

656 determined at $120 \mathrm{~h}$ using the Promega ${ }^{\mathrm{TM}}$ CytoTox $96^{\mathrm{TM}}$ assay kit, and values represent the average of the three independent experiments.

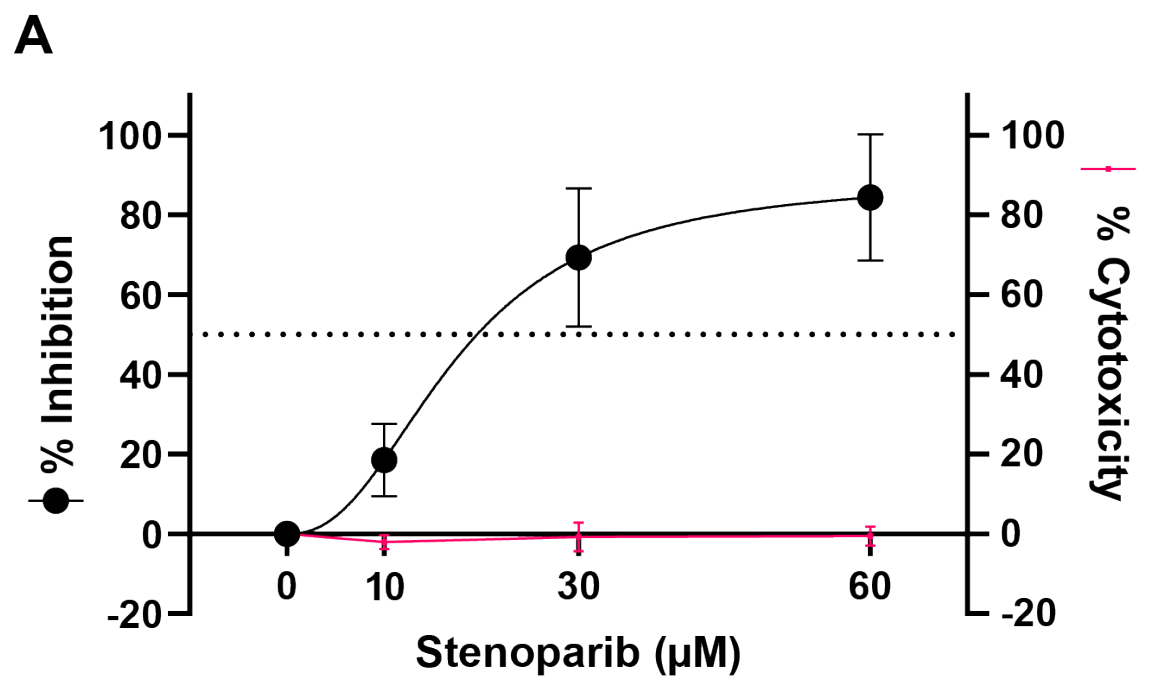

B

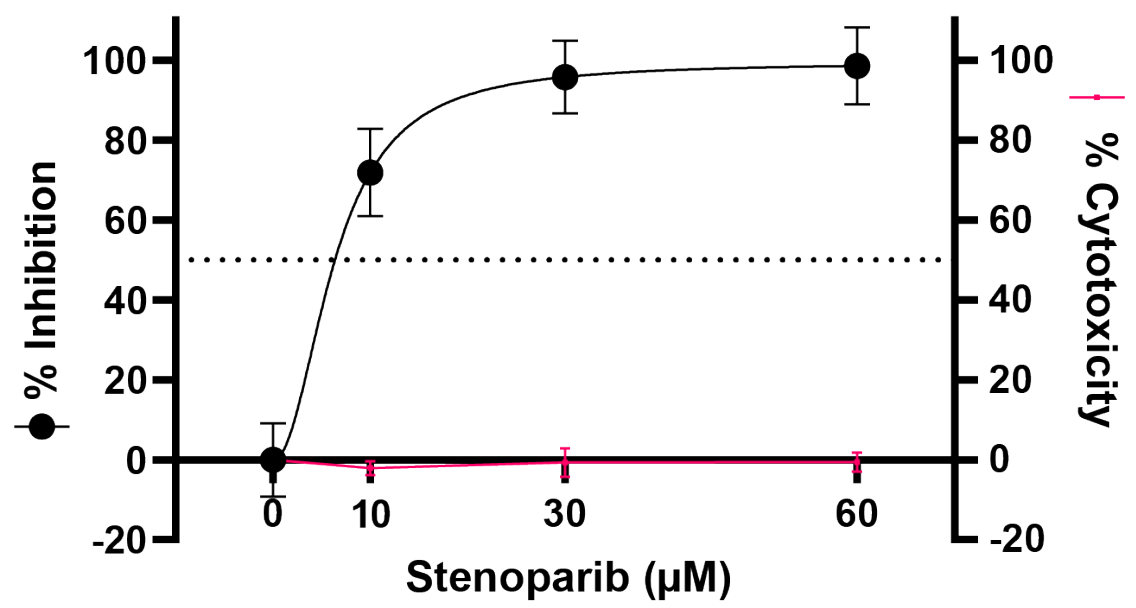


Fig. 5. Stenoparib inhibits HCoV-NL63 entry and post entry events while remdesivir inhibits post-entry. A) Plaque assays were performed three times and replicate plaque forming unit counts from each run were averaged. Error bars are based on standard deviation among runs.

666 Brackets indicate the t-test comparison and P-value for the "Entry" group. No significant difference was observed between stenoparib and remdesivir under any treatment. N/D indicates that no plaques were detected in these treatment groups. B) RT-qPCR was performed on viral RNA collected from cell culture media at $120 \mathrm{~h}$ post infection and replicate values within each run were averaged; a total of three runs were performed. Error bars were based on averaged standard deviations within runs. Brackets indicate the t-test comparison and P-value for the "Entry" group. Significant differences were observed between stenoparib and remdesivir under all treatments.

\section{A}

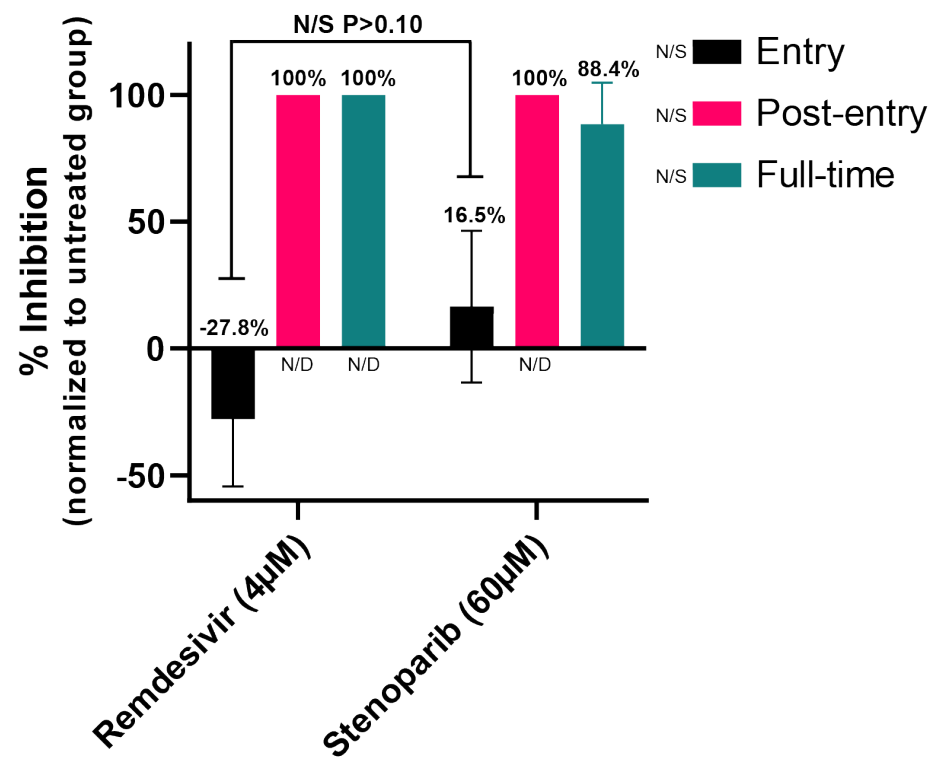

B

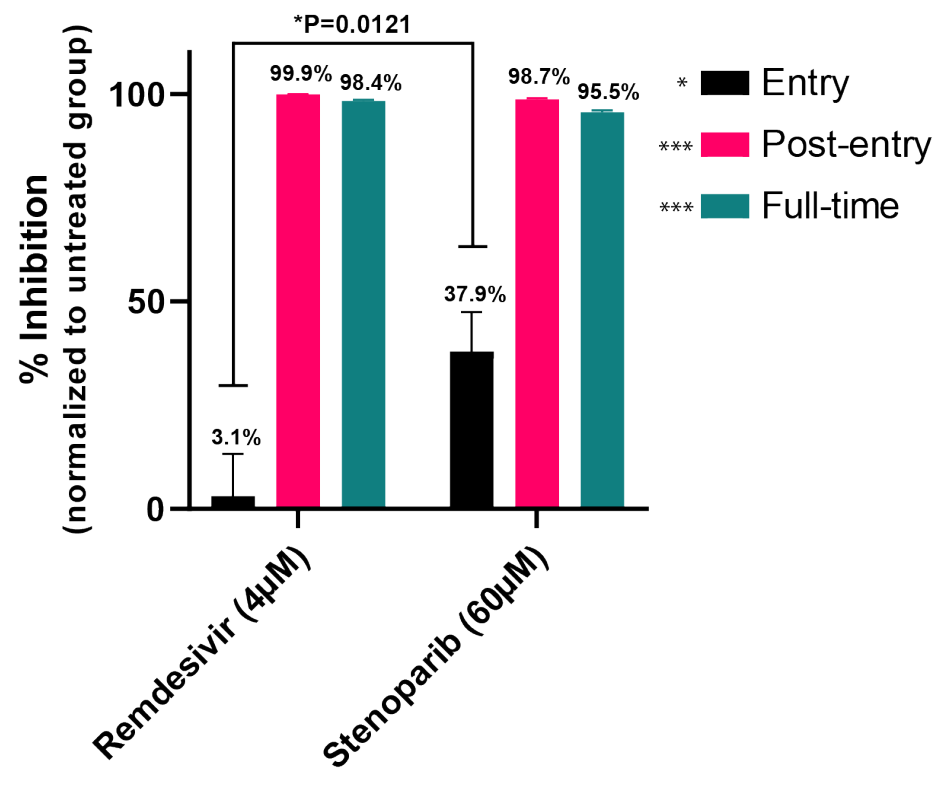


Fig. 6. Stenoparib and remdesivir in combination is a potent inhibitor of NL63. Plaque assays were performed a minimum of two times and replicate values from each run were averaged. Plaquing efficiency values are normalized as a percentage of inhibition compared to infected, but untreated cells. Three data sets are plotted to illustrate the treatment of NL63 with 1) stenoparib and 2) remdesivir as monotherapies and as a 3) combination therapy, whereby increasing concentrations of stenoparib are combined with $0.5 \mu \mathrm{M}$ remdesivir; the $\mathrm{EC}_{50}$ was computationally approximated at $0.46 \mu \mathrm{M}$. The stenoparib monotherapy data is the same as previously reported (Fig. 4A). The synergistic activity threshold is defined as the sum of the mean values of $10 \mu \mathrm{M}$ stenoparib and $0.5 \mu \mathrm{M}$ remdesivir as monotherapies, while the grey highlighted area represents the minimum and maximum possible additive activity values based on the range of error for those same concentrations observed during these experiments.

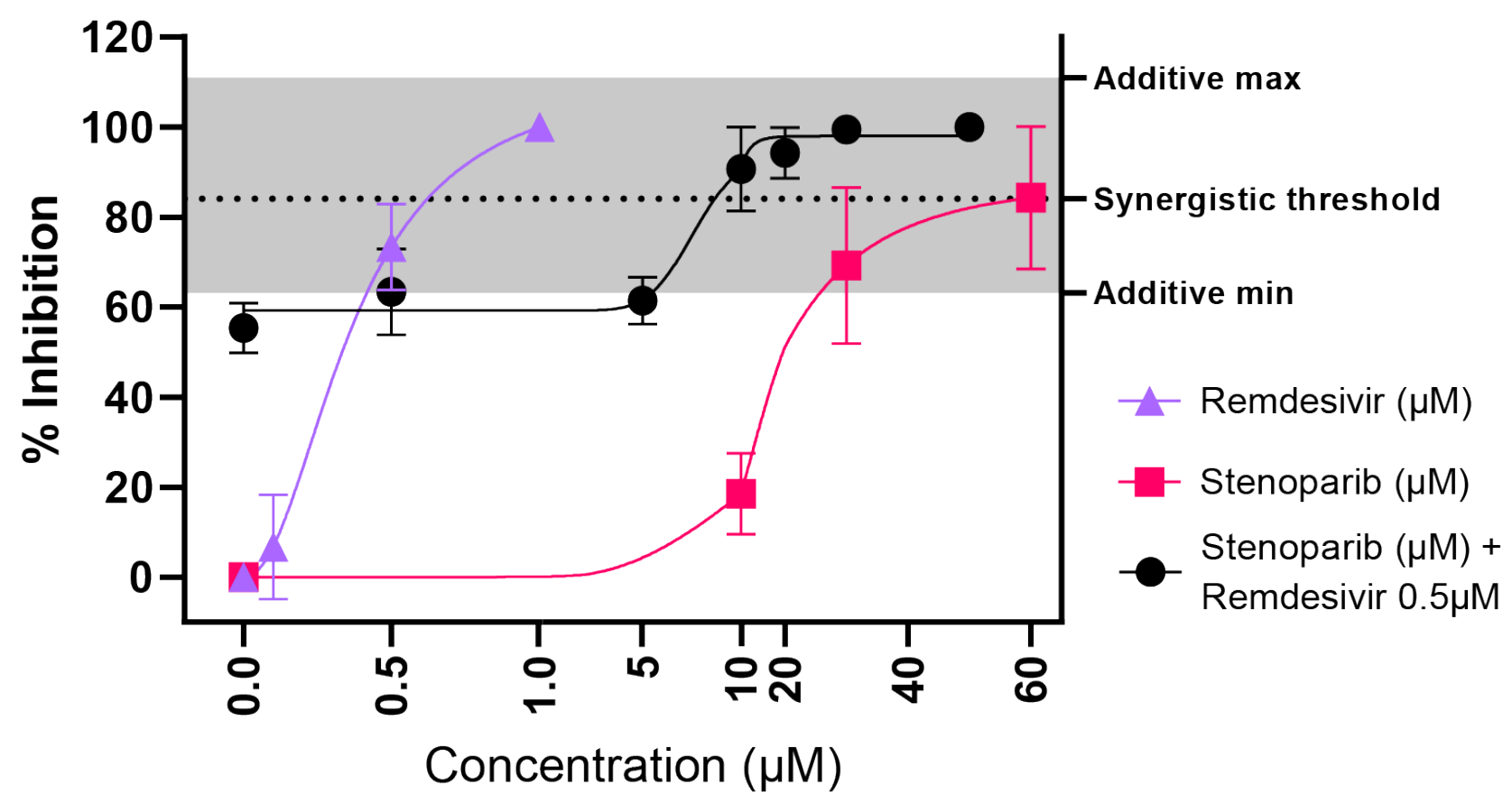

688 
Fig. S1. Stenoparib inhibits plaque formation in Calu-3 cells. Plaque assays were performed using Calu-3 cells infected with SARS-CoV-2 and treated with varying concentrations of stenoparib. Plaques are identified as empty regions or "dead zones" in the cellular monolayer and are expressed as plaque forming units (PFUs) per well. Plaques were manually counted and averaged among experimental replicates. This score is normalized as a percentage of untreated, but infected cells. In this representative image of the SARS-CoV-2/Calu-3 experiment, plaques are dark scars on the cellular monolayer. Controls were 1) uninfected cells (Cell Ctl), 2) untreated, but infected cells $(0 \mu \mathrm{M})$, and 3$)$ a camostat mesylate and E64d $(\mathrm{C} / \mathrm{E})$ inhibitor control (Inhibitor Ctl). Treatment with stenoparib at $10 \mu \mathrm{M}$ and $30 \mu \mathrm{M}$ led to a marked reduction in plaquing efficiency, whereas $60 \mu \mathrm{M}$ resulted in near complete inhibition.

Cell Ctl (no virus)

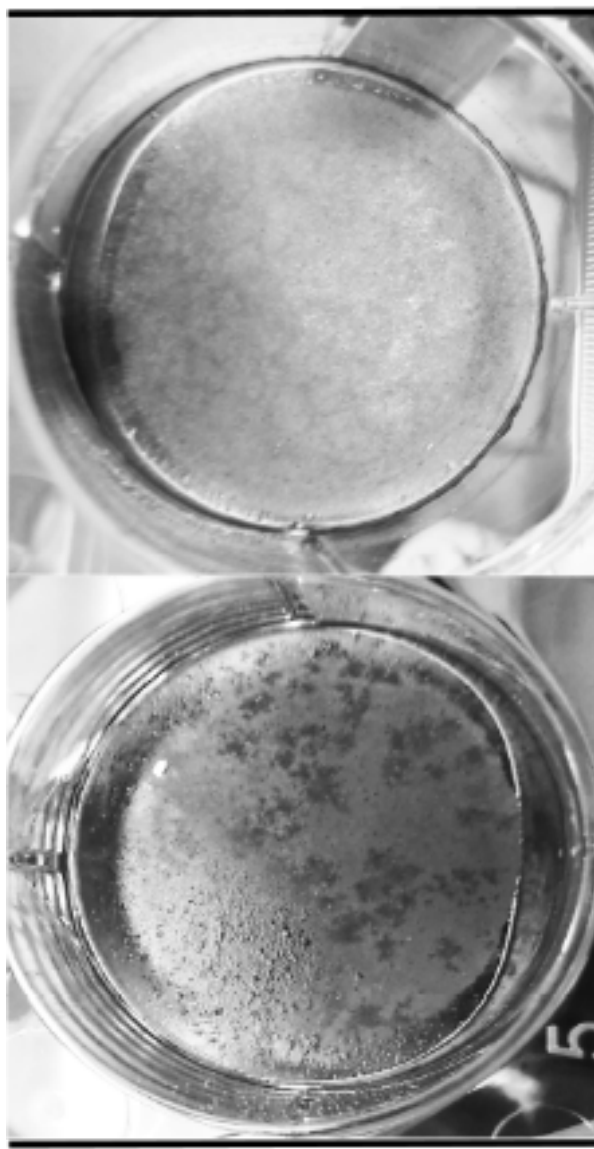

$30 \mu \mathrm{M}$ Stenoparib

\section{0 $\mu \mathrm{M}$ Stenoparib}

$10 \mu \mathrm{M}$ Stenoparib

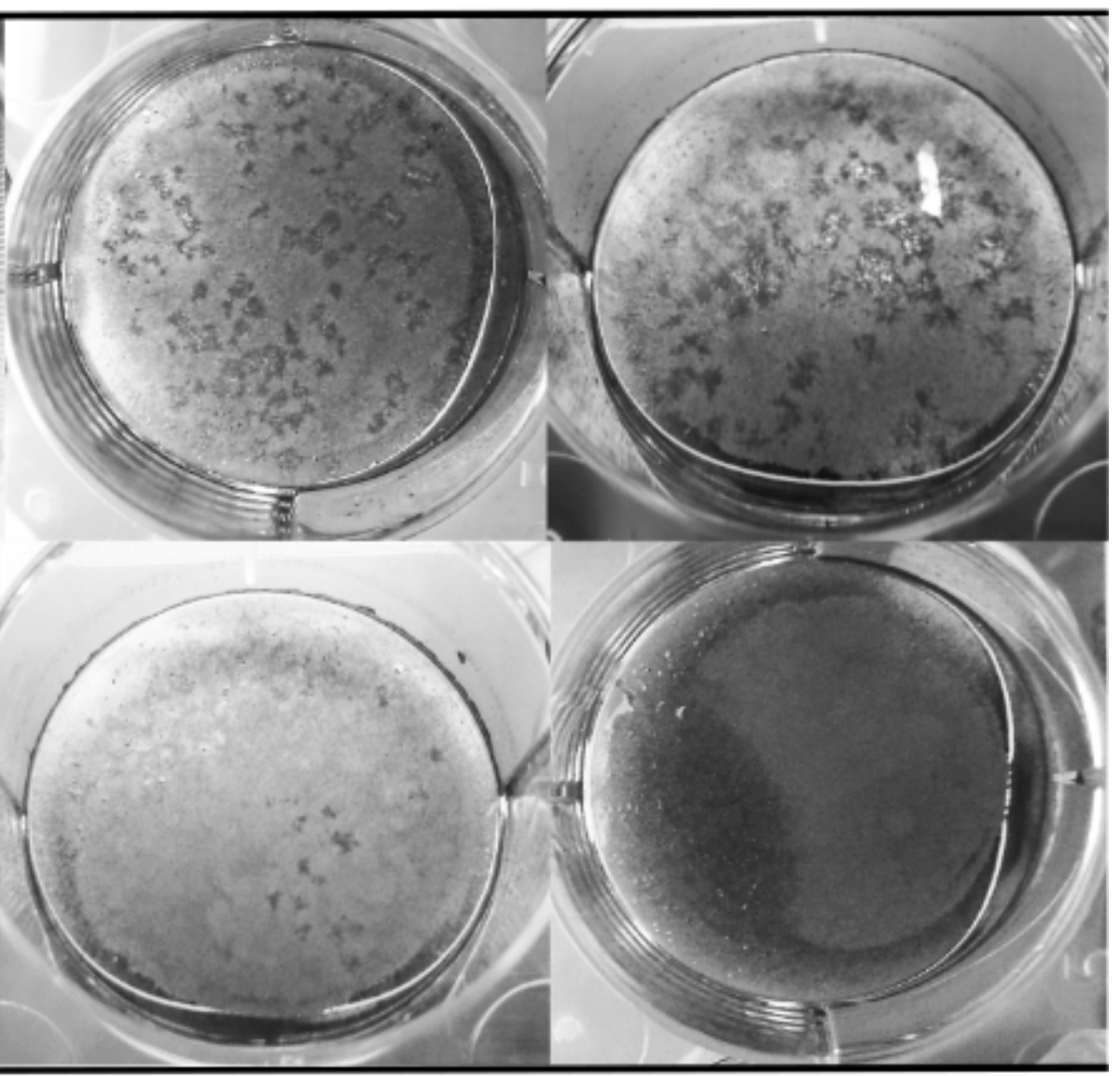

$60 \mu \mathrm{M}$ Stenoparib 